\title{
Trends in Regional Inequalities in Pakistan: Evidence Since 1998
}

\section{Sajjad Akhtar*}

\begin{abstract}
Periodic research and documentation of the extent and nature of inter-regional and intra-regional inequalities is a pre-requisite for formulating cost effective interventions for the promotion of spatially balanced and sustainable development. These interventions can be in the shape of increased fiscal resource transfers and/or fiscal incentives to the private sector for promoting investments in lagging regions. The analysis of inter-regional and intra-regional consumption and non-consumption inequalities in this paper are a preliminary attempt at assessing their status.
\end{abstract}

JEL Classification: D31, E21

Keywords: Pakistan, Inequality, Consumption, Social Indicator

\section{Introduction}

In Pakistan, serious academic research and debate on regional economic and non-economic performance has lagged behind other topics partly because of its structure and division at the sub-national level. The province of Punjab roughly contains 50 percent of the population and the rest of 3 provinces, i.e., Sindh, North West Frontier Province (NWFP) and Baluchistan, the remaining 50 percent population, which has generated an inherent concentration in terms of political representation and translated into a "smaller provinces versus the bigger province" syndrome. The protection of 'inverted pyramid' social and economic interests has not only discouraged the timely release of quantity and quality of data from the Federal statistical agencies, but the quality of data generated by statistical departments at the regional level has also been called into question. Consequently under perceived 'political expediency' and in the interest of bridging the 'provincial and northsouth divide' the research into regional inequities is generally

\footnotetext{
* Director of Center for Research on Poverty Reduction and Income Distribution, Planning Commission, Pakistan.
} 
discouraged and whatever is published (mostly in foreign journals) is mostly looked upon as politically motivated to further the interests of a particular province or region. Viewed against this backdrop, this empirical research hopes to make a modest contribution towards an understanding of the regional inequalities during the last decade.

Interregional inequalities can be traced to a complex set of historical and geographical factors, which can be labeled as "structural". As discussed in the World Development Report (WDR) 2006, "Weak resource endowments and distance from markets can constrain development in lagging regions. In many cases, economic differences are linked with longstanding, unequal relations of power between advantaged and lagging regions, and institutional weaknesses within the latter." Concentration of disadvantaged ethnic, racial, and social groups in particular regions cause group-based inequities and then lead to regional inequalities. In poor regions, where regional elites hijack power, decentralization may also deepen both intra- and inter-regional inequalities.

As a first step, balanced and sustainable development entails that attempts at the policy, planning and implementation level be geared towards minimizing the economic and social/human capital inequalities between the backward and more developed regions of the country. Pakistan, in spite of being a middle income country, shows considerable variation in development across sub-national levels. Two of its provinces i.e., Baluchistan and NWFP, are relatively less developed than Punjab and Sindh. Within Punjab, southern Punjab lags behind its northern part in socio-economic development. Within Sindh, rural-urban divide in development is more visible than in the case of Punjab. A limitation of interregional analysis using provinces as units is the fact that this may not be able to capture the significant intra-province disparities in economic and social development. After discussing inter-provincial disparities, we briefly analyze intra-Punjab disparities in social indicators between 1998 and 2005.

\section{Inter-Provincial and Interregional Poverty Differentials}

The spatial equilibrium school which has much in common with neo-classical theory claims that regional inequality is a 'temporary phenomenon". Over time, economic growth of different regions will converge. The "divergence" hypothesis holds that spatial distribution of economic development leans towards inequality and that market forces tend to increase regional inequality rather than decrease it. Thus, only public intervention is capable of reducing regional inequality. Empirically it may be 
difficult to separate these two phenomena, as most countries continue to intervene to develop the lagging regions.

In the absence of good quality and long-term data on economic growth rates for the 4 provinces of Pakistan, we rely on the outcome variables i.e., poverty levels and consumption inequalities for the last few years, to undertake a stylized assessment of the convergence or divergence hypothesis. Table-1 gives the poverty headcount based on consumption welfare for the years 98-99, 00-01 and 04-05 for Pakistan and for the provinces by rural/urban classification. As the government is still reluctant to release provincial poverty headcounts for the year 04-05, consistent estimates of the World Bank are reproduced here for the provinces for all the 3 years. While the percentage of poor have fallen from 31.1 percent in 98-99 to 23.9 percent in 2004-05, after rising marginally to 34.5 in 2000 01 , the same trend is observed in the gap between urban and rural poverty at the national level. The difference between the rural and urban headcount fell to 13.2 percentage points in 2004-05 from 13.6 in 1998-99 after rising to 16.6 in 00-01. Assuming that the years $00-01$ and $04-05$ were both extreme points with regard to growth rates and agriculture performance, one can say very little about convergence or divergence on the basis of the single normal year of 98-99. Preliminary analysis of the 2005-06 data suggests a renewed widening of the rural-urban gap in headcounts at the national level.

Table-1: National and Provincial Trends in Headcount by Urban/Rural

\begin{tabular}{lccccccccc}
\hline & \multicolumn{3}{c}{ 1998-99 } & \multicolumn{3}{c}{ 2000-01 } & \multicolumn{3}{c}{ 2004-05 } \\
\hline & $\mathbf{U}$ & $\mathbf{R}$ & $\mathbf{T}$ & $\mathbf{U}$ & $\mathbf{R}$ & $\mathbf{T}$ & $\mathbf{U}$ & $\mathbf{R}$ & $\mathbf{T}$ \\
\hline Pakistan & 21.4 & 35.1 & 31.1 & 22.7 & 39.3 & 34.5 & 14.9 & 28.1 & 23.9 \\
Punjab & 23.70 & 32.20 & 29.80 & 23.00 & 33.80 & 30.70 & 21.20 & 33.4 & 29.5 \\
Sindh & 15.30 & 34.50 & 26.20 & 20.70 & 48.30 & 37.50 & 13.80 & 28.9 & 22.4 \\
N.W.F.P & 26.10 & 43.30 & 40.80 & 30.00 & 44.40 & 42.30 & 26.10 & 41.9 & 39.3 \\
Baluchistan & 25.20 & 21.60 & 22.10 & 27.40 & 39.30 & 37.20 & 21.50 & 35.8 & 32.9 \\
\hline
\end{tabular}

Source: Author's Calculation

Before analyzing the provincial poverty trends, a caveat is in order for the province of Balochistan. Given its vast physical area and just 5 percent of total population, the sampling errors are likely to be greater than other provinces, even though the provincial sample is representative. The 
impressive growth in Punjab's GDP since FY02-03, ranging from 5.8 percent in 02-03 to 9.35 percent in 04-05, as per estimates of its Bureau of Statistics, is reflected in estimates of poverty headcount. Its poverty headcount improved by approximately 8 percentage points from 32.2 percent in 00-01 to 24.3 percent in 04-05. A significant decline occurred in the province of Sindh where overall poverty nearly halved from 35.3 percent in $00-01$ to 18.3 in $04-05^{1}$. The next highest fall of 9.2 percentage points occurred in NWFP in line with the national decline. The provincial profile of poverty headcounts indicate that NWFP consistently has the highest number of people living below the poverty line. The ratio of the NWFP headcount and the province with lowest headcount fluctuated between 1.91 - 1.28, with no narrowing of the gap. The urban-rural gap in headcounts is the widest in the province of Sindh, where the rural headcount is almost twice that of those prevailing in urban areas. The poverty headcount differentials between NWFP and Balochistan continued to narrow during the period.

\section{Inter and Intra-Provincial Consumption Disparities}

In Table-2, we give the national trends in consumption based Gini coefficients for the four years. Although disparities in consumption are lower than income based disparities, they have risen consistently since 00-01. At 0.3018 in $05-06$, they are now at the same level as they were in 98-99. The provincial Ginis are given as a multiple of the national Gini coefficient. Consumption disparities in the province of Sindh and Punjab remain higher than the national ones in most of the years, with no discernible narrowing over the years under observation. Although consumption within NWFP and Baluchistan is more equal than within Pakistan, there is a tendency of 'catching up' or 'emulating' the national disparities in both provinces in recent years as compared to 98-99 and 00-01. Moreover, it is observed that disparities tend to narrow in times of poor economic growth and widen in times of above average economic performance. This relationship between consumption disparities, and specifically agricultural output, is understandable given the existence of a large number of subsistence farmers in the country and because a majority of the population remains close to the poverty line.

\footnotetext{
${ }^{1}$ Using a different methodology to calculate the poverty headcount, World Bank estimates also show wide fluctuations for Sindh during the period. For overall Sindh their estimates are: $26.2 \%$ (1998-99), $37.5 \%(2000-01)$ and $22.4 \%$ (2004-05).
} 
Table-2: Consumption Based Gini Coefficients

\begin{tabular}{lcccc}
\hline & $\mathbf{1 9 9 8 - 9 9}$ & $\mathbf{2 0 0 0 - 0 1}$ & $\mathbf{2 0 0 4 - 0 5}$ & 2005-06 \\
\hline Pakistan & 0.3019 & 0.2752 & 0.2976 & 0.3018 \\
Punjab & 1.026 & 0.99 & 1.02 & 0.99 \\
Sindh & 1.021 & 1.10 & 1.01 & 1.05 \\
NWFP & 0.89 & 0.82 & 0.85 & 0.87 \\
Baluchistan & 0.77 & 0.75 & 0.80 & 0.81 \\
\hline
\end{tabular}

The time profile of quintile ratios at the national and provincial levels in Table-3 further reinforces the findings of the Gini coefficients. At the national level, the ratio of the top $20 \%$ consumption quintile to the bottom $40 \%$ quintile at 1.8 is the same in $05-06$ as it was in 98-99. In Punjab and NWFP this ratio has increased since 98-99, while in the province of Sindh and Baluchistan it declined.

Table-3: Ratio of Top $20 \%$ to Bottom $40 \%$

\begin{tabular}{lcccc}
\hline & 1998-99 & 2000-01 & 2004-05 & 2005-06 \\
\hline Pakistan & 1.8 & 1.6 & 1.7 & 1.8 \\
Punjab & 1.9 & 1.9 & 1.9 & 2.2 \\
Sindh & 2.3 & 1.7 & 2.4 & 1.9 \\
NWFP & 0.8 & 0.8 & 0.8 & 0.9 \\
Baluchistan & 1.9 & 0.9 & 0.8 & 0.3 \\
\hline
\end{tabular}

\section{Development Assistance to Provinces}

In order to achieve 'convergence' in growth rates and per capita incomes, governments not only offer fiscal incentives for increasing private investment in lagging regions but also increase public investment in those regions. In the absence of data on the provincial breakdown of private investment in Pakistan, a time series of federal development assistance to finance provincial development programs is analyzed to assess the imbalances in the resource transfer to provinces for the purpose of 'catching up'.

Inter-governmental transfers in Pakistan are governed by the National Finance Commission (NFC) awards which are theoretically to be revised and announced every five years. The last NFC award was announced in 1997 and continues till now with a slight modification in 2005. The 1997 NFC expanded the divisible pool of taxes to include all federal taxes. 
Prior to this, according to the 1991 NFC award, only revenues from the income tax, sales tax and excise duties on sugar, tobacco and tobacco manufactures were shared with the provinces. However, the expansion in the pool was accompanied by a contraction in the overall provincial share from 80 percent to $37.5 \%$. Also, in recognition of relative backwardness and lack of taxable capacity, the NFC award of 1997 greatly increased the quantum of special grants to Baluchistan and NWFP. The divisible pool is shared on the basis of the population share of each province. Though resource transfers to provinces are theoretically governed by NFC awards, the federal assistance to development programs that are meant to increase the economic and social infrastructure of the provinces is not only sensitive to revenues of the Federal government but also to foreign project assistance.

Table-4 gives the shares of provinces in the Federal assistance towards provincial development expenditure from 96-97 to 06-07. Only in 03-04, the assistance to Punjab comes close to its population share of 55 percent. The lagging provinces, i.e., NWFP and Baluchistan have consistently received higher shares than their population share in the shape of grants from the Federal government, partly offsetting the interest of private investors, and in case of Baluchistan unit cost of investment in the social sector are higher due to the spread of $5 \%$ population over a very large area. Sindh's share in assistance has been fluctuating around its population share for 6 out of 11 years. The share trends for each province indicate that variability is the highest for Sindh ranging from $8.5 \%$ in $01-02$ to 35.6 percent in 96-97 followed by Baluchistan.

Development assistance by the federal government to provinces is closely linked with foreign project assistance and is thus partly a function of economic and non-economic interests (temporary as well permanent) of development partners in the development of each province. Table- 5 shows that foreign project assistance in any year did not fall below $50 \%$ of the federal assistance. For 7 out of 11 years, the foreign project assistance hovered above 85 percent. Fortunately, the share pattern of foreign project assistance to the provinces closely mirrors the shares in Table- 4 , and is not sensitive to falls in foreign development aid.

Table- 6 gives the federal assistance in terms of per capita population of the provinces. At the national level, the per capita development assistance fluctuated between Rs. 86 to Rs. 215 during the 11 years. Punjab's per capita receipt is consistently below the national average while that of NWFP and Baluchistan has been at roughly twice of the national per capita receipt during the eleven years. 


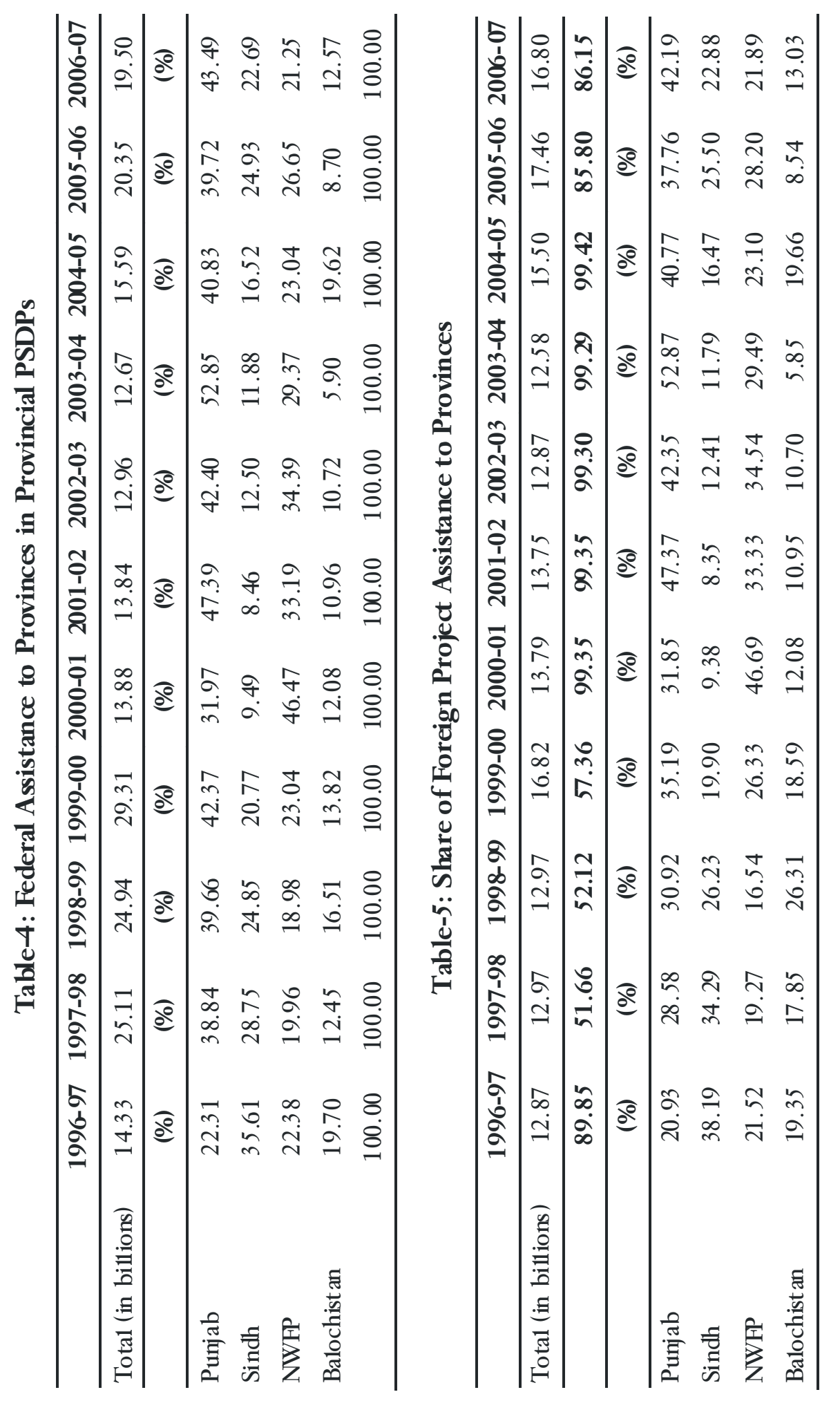


Table-6: Federal Assistance Per Capita

\begin{tabular}{lccccccccc}
\hline & $\mathbf{1 9 9 8 - 9 9}$ & $\mathbf{1 9 9 9 - 0 0}$ & $\mathbf{2 0 0 0 - 0 1}$ & $\mathbf{2 0 0 1 - 0 2}$ & $\mathbf{2 0 0 2 - 0 3}$ & $\mathbf{2 0 0 3 - 0 4}$ & $\mathbf{2 0 0 4 - 0 5}$ & $\mathbf{2 0 0 5 - 0 6}$ & $\mathbf{2 0 0 6 - 0 7}$ \\
\hline Nationa1 & 183.01 & 215.09 & 97.76 & 97.48 & 89.51 & 85.78 & 103.51 & 132.62 & 124.77 \\
Punjab & 130.52 & 163.87 & 56.28 & 83.18 & 68.40 & 81.81 & 76.35 & 95.31 & 98.30 \\
Sindh & 197.63 & 194.18 & 40.34 & 35.87 & 48.69 & 44.41 & 74.46 & 143.88 & 123.33 \\
N.W.F.P & 258.42 & 368.68 & 336.35 & 239.56 & 227.23 & 185.36 & 175.15 & 259.09 & 193.69 \\
Baluchistan & 607.50 & 597.82 & 235.85 & 213.41 & 190.76 & 100.22 & 400.34 & 226.59 & 306.29 \\
\hline
\end{tabular}

Regional Inequalities: A Look at the Non-Income Inter- and IntraProvincial Disparities

One way to assess the net outcome of all federal and donors' intervention aimed at more balanced spatial development in the country is to understand what is happening to the disparities in social indicators across and within provinces, as ultimately the end result of all interventions is to increase the capacities of local populations to attain a higher standard of living. Table-7 gives the inter-provincial status of 12 social and quality of living indicators (7 are Millennium Development Goals (MDG) indicators) in 2005. District-level representative PSLM 2004-05 sample of 77,000 households is the source for these un-weighted estimates. In 9 indicators that are positively related to level of development (except deprivation indicators such as level of congestion as measured by one room houses and use of wood as cooking fue1), Punjab's averages are higher than the national average. Sindh's averages are close, while Baluchistan's averages are below national averages. NWFP's averages, except for youth GPI, drinking water supply and use of gas/ kerosene oil, are also close to the national average. In level of congestion as reflected in one room houses, Sindh's average is 60 percent higher than the national average and Baluchistan's and NWFP's average is lower than the national average. Higher use of wood for cooking purposes in NWFP and Baluchistan raises their provincial average above the national average. 
Table-7: Social and Quality of Living Indicators in 2005

\begin{tabular}{lccccc}
\hline Indicators & Pakistan & Punjab & Sindh & NWFP & Baluchistan \\
\hline Net Primary & 48 & 59 & 45 & 46 & 36 \\
Enrolment & & $(1.23)$ & $(0.94)$ & $(0.96)$ & $(0.75)$ \\
Literacy Rate & 45 & 53 & 48 & 43 & 34 \\
10 yrs & & $(1.18)$ & $(1.07)$ & $(0.95)$ & $(0.75)$ \\
GPI NER & 0.76 & 0.90 & 0.74 & 0.70 & 0.64 \\
& & $(1.18)$ & $(0.97)$ & $(0.92)$ & $(0.84)$ \\
Youth & 0.54 & 0.74 & 0.57 & 0.42 & 0.34 \\
Literacy GPI & & $(1.37)$ & $(1.05)$ & $(0.78)$ & $(0.63)$ \\
Immunization & 75 & 86 & 70 & 77 & 61 \\
& & $(1.15)$ & $(0.93)$ & $(1.03)$ & $(0.81)$ \\
Water Supply & 63 & 91 & 76 & 47 & 30 \\
& & $(1.44)$ & $(1.21)$ & $(0.75)$ & $(0.48)$ \\
Sanitation & 69 & 66 & 80 & 73 & 63 \\
& & $(0.96)$ & $(1.16)$ & $(1.06)$ & $(0.91)$ \\
Home & 89 & 89 & 89 & 85 & 92 \\
Ownership & & $(1.0)$ & $(1.0)$ & $(0.96)$ & $(1.03)$ \\
Level of & 22 & 24 & 35 & 19 & 16 \\
Congestion & & $(1.09)$ & $(1.59)$ & $(0.86)$ & $(0.73)$ \\
Electricity & 62 & 69 & 61 & 69 & 45 \\
& & $(1.11)$ & $(0.98)$ & $(1.11)$ & $(0.45)$ \\
Pop. using & 18 & 23 & 22 & 15 & 12 \\
Gas/K. Oil & & $(1.28)$ & $(1.22)$ & $(0.83)$ & $(0.67)$ \\
Wood as & 70 & 54 & 69 & 82 & 81 \\
cooking fuel & & $(0.77)$ & $(0.99)$ & $(1.17)$ & $(1.16)$ \\
\hline
\end{tabular}

The question whether disparities between provinces in access to social services as well as quality of living have been reduced over time can be answered by comparing the differential between the highest and lowest scoring province for each of the indicators in the two years. Table- 8 converts the lowest score as a proportion of the highest score. Overtime if this proportion rises then disparities narrow between the top and bottom ranking provinces for the respective indicator. Out of 10 indicators, interprovincial disparities decreased in 5 indicators between 98-99 and 04-05. In home ownership, inequities remained stable while in access to electricity it only improved marginally. GPI in primary net enrolment and immunization decreased marginally. 
Table-8: Disparities in Social Indicators

\begin{tabular}{llccccc}
\hline \multicolumn{1}{c}{ Pakistan } & Pakistan & Punjab & Sindh & NWFP & Baluchistan \\
\hline 1 & Net Primary Enrolment & $(-)$ & $(-)$ & $(-)$ & $(-)$ & $(-)$ \\
2 & Literacy Rate 10 Years \& & $(-)$ & $(-)$ & $(-)$ & $(-)$ & $(-)$ \\
& Above & & & & & \\
3 & GPI in Net Enrolment & $(=)$ & $(=)$ & $(-)$ & $(-)$ & $(=)$ \\
& (Primary) \\
4 & Youth Literacy GPI & $(+)$ & $(-)$ & $(-)$ & $(=)$ & $(+)$ \\
5 & Immunization Coverage & $(=)$ & $(-)$ & $(+)$ & $(=)$ & $(=)$ \\
6 & Drinking Water Supply & $(-)$ & $(-)$ & $(-)$ & $(=)$ & $(-)$ \\
7 & Sanitation & $(-)$ & $(-)$ & $(-)$ & $(-)$ & $(-)$ \\
8 & Home Ownership & $(-)$ & $(=)$ & $(-)$ & $(-)$ & $(-)$ \\
9 & Level of Congestion (One & $(=)$ & $(+)$ & $(+)$ & $(+)$ & $(=)$ \\
& Room) & & & & & \\
10 & Electricity & $(-)$ & $(-)$ & $(-)$ & $(-)$ & $(-)$ \\
11 & Proportion of Population & $(-)$ & $(-)$ & $(-)$ & $(-)$ & $(=)$ \\
& using Gas/K. Oil & & & & & \\
12 & Wood as Cooking Fuel & $(+)$ & $(+)$ & $(+)$ & $(+)$ & $(=)$ \\
& Reduced Disparities & 7.00 & 7.00 & 9.00 & 7.00 & 6.00 \\
\hline
\end{tabular}

Note: (-) Reduced, (+) Widening, (=), Unchanged

Whether intra-national/provincial disparities have decreased can be answered by using the Census 1998 since household data on same set of comparable indicators was collected at that time. Table-9 gives a snapshot of the status of disparities at the national and provincial level between the two points in time. The coefficient of variation is used as a proxy measure to assess the reduction $(-)$, widening $(+)$ and unchanged $(=)$ disparities during the period. In 7 out of 12 indicators, a closing of gap is observed among 98 districts at the national level. These include net primary enrolment, literacy rate 10 years and above, gender parity Index (GPI) in net primary enrolment, water supply, sanitation, electricity coverage, home ownership and population using gas/kerosene oil for cooking. Within Punjab and Sindh provinces, disparities declined among all the education indicators, as well as in access to utilities during the period. In the case of Punjab, inequities in immunization coverage also declined. The widening of disparities in the 
deprivation indicators in the provinces can reflect: a) reduced number of areas with poor access to social and utilities access or b) continued existence of pockets of extreme poverty.

Table-9: Share of Allocations to (Punjab) Region's Districts

\begin{tabular}{lcccccc}
\hline & FY & FY & FY & FY & FY & FY \\
& 2001-02 & 2002-03 & 2003-04 & 2004-05 & 2005-06 & 2006-07 \\
\hline $\begin{array}{l}\text { Northwest } \\
\text { Punjab }\end{array}$ & $24.05 \%$ & $18.09 \%$ & $17.21 \%$ & $18.13 \%$ & $17.49 \%$ & $17.93 \%$ \\
$\begin{array}{l}\text { Central } \\
\text { Punjab }\end{array}$ & $49.37 \%$ & $56.88 \%$ & $57.44 \%$ & $56.60 \%$ & $56.52 \%$ & $55.63 \%$ \\
$\begin{array}{l}\text { South } \\
\text { Punjab }\end{array}$ & $26.58 \%$ & $25.02 \%$ & $25.35 \%$ & $25.26 \%$ & $25.98 \%$ & $26.44 \%$ \\
\hline
\end{tabular}

Some of the major findings from the district-wise analysis contained in MDG Report (2006) are as follows:-

- District-wise analysis of seven MDG indicators reveals that in six indicators, the majority of districts in the top-ten districts are from Punjab in 2005. In comparison to 1998, there are fewer districts of Punjab now among the top ten elite groups in three out of seven indicators.

- Districts in Baluchistan and NWFP dominate the bottom ten rankings. However comparing the 1998 with the 2005 rankings, many districts of NWFP made remarkable improvements in GPI primary enrolment, youth literacy and sanitation and districts in Baluchistan took their place in 2005 by default or slow improvements.

- In four indicators, districts of Baluchistan dominate the ranking of the fastest growing districts during the period. In the remaining three indicators, districts of NWFP dominate the ranking of fastest growing districts. Ranking of districts by absolute improvement in indicators also yields very similar results.

- A study by CRPRID (2007) constructed a composite index of the twelve indicators using the technique of factor analysis. A comparative ranking of districts by weighted factor scores for the years 1998 and 2005 revealed that in 1998, eight districts from Punjab were among the top ten scoring districts. By 2005 none of the districts from the other three provinces were in the list of top ten scorers. 
- In 1998, among the ten lowest scores, five belonged to Baluchistan and four to NWFP. By 2005, the number of districts from Baluchistan increased to seven, and number of districts in NWFP reduced to two.

\section{Intra-Punjab Inequalities}

In the absence of district level GDP and growth data, we assess the intra-Punjab inequities from two different angles. The 34 districts of Punjab are categorized into three regions, North West $(8$ districts), South (9 districts) and Central (17 districts) ${ }^{2}$. We first examine the shares of these three regions in the allocation of expenditures to district councils for the period 01-02 to 06-07 in Table-10. The districts belonging to the Northwest region received between 17-24 percent of total allocations, while those in Central Punjab received between 50-60 percent. The Southern region receiving the remaining 25 percent share. One can only conjecture, given small variability in these shares over the last 6 years, that they are strictly based on population shares. No deliberate attempts were made by the provincial government via grants or other fiscal resource transfers to increase public investments to compensate for the 'backwardness' of southern Punjab. No doubt, estimates of per capita allocations or a breakup of expenditures into current and development would give a more informed picture of the inequities in intra-Punjab allocations.

Table-10 summarizes the status of disparities in non-income dimensions for the three regions. The last column gives the status of interregional disparities within Punjab. Out of 12 indicators, the coefficient of variation was smaller for seven indicators in 2005 compared to 1998. Disparities in youth literacy, immunization coverage and one room houses remained unchanged. For eight indicators, the F-test for equality of means for the regions is significant. In other words, the means reflect different underlying population characteristics. The remaining columns indicate that intra-regional disparities in a majority of the indicators declined during the 1998-2005 period in Punjab.

\footnotetext{
${ }^{2}$ The list of districts in each of these categories is given in the Appendix.
} 


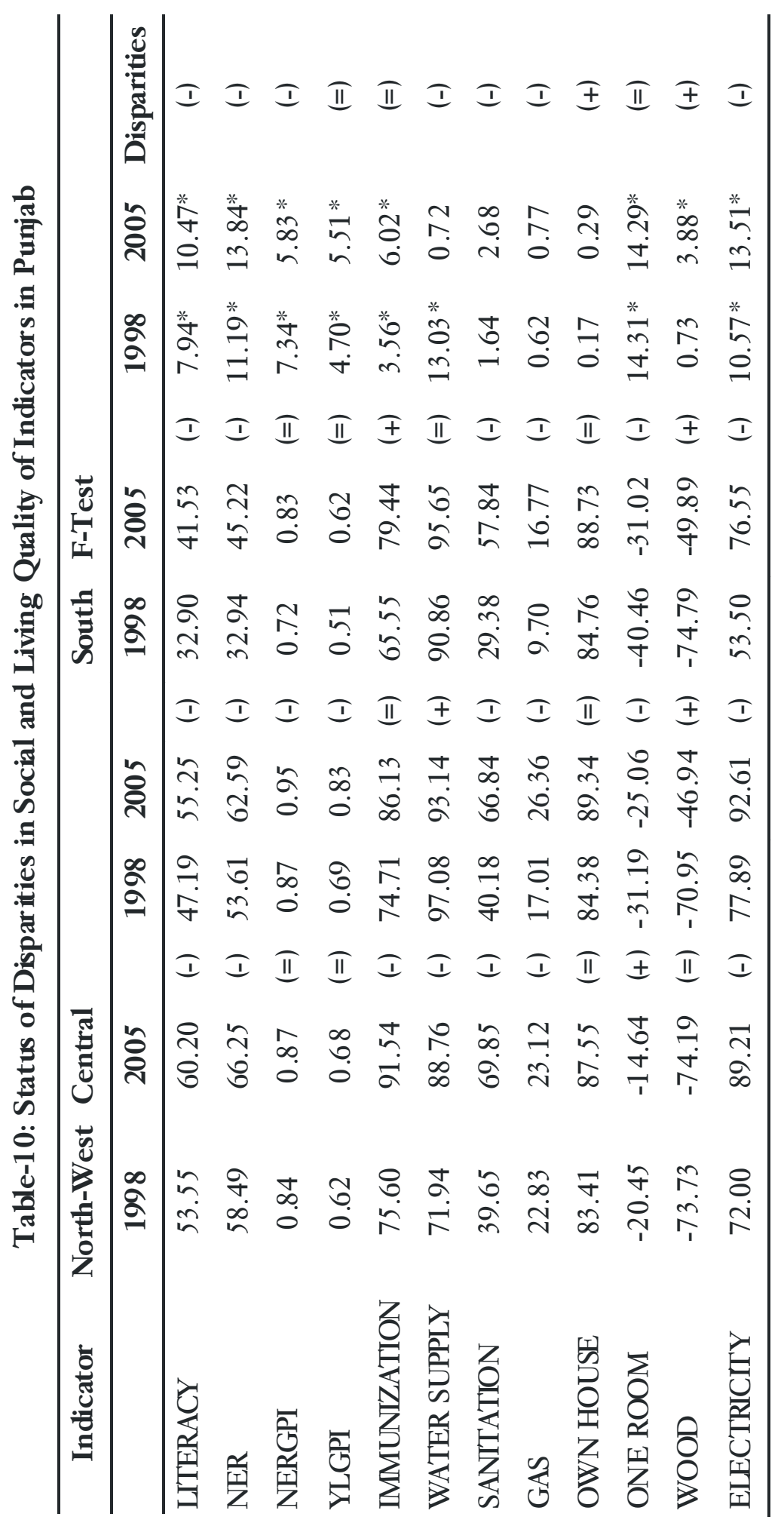




\section{Summary and Conclusions}

During the last few years, economic performance at the national level has reduced absolute poverty levels significantly from 1998-99 levels as per official statistics. The reduction has also filtered down to the urban and rural areas of the four provinces, although in varying degrees. However at the same time, it is accepted that income and consumption inequalities increased during the same period and they stand at the same level as in 1998-99. The rise in consumption inequalities during 1998-99 and 2004-05 are empirically documented, while documentation of rising income inequalities awaits data analysis. The status of intra-regional inequalities is another inquiry that needs to be undertaken.

Relying on official statistics and data, this study is a modest attempt at providing a snap-shot of consumption and non-consumption based inequalities from the period 1998-99 onwards. The main findings can be summarized as follows:

a) Improved economic performance at the national level during the last few years is reflected in a decline in poverty levels at the national level and provincial level. Punjab's poverty levels improved by 7 percentage points during 2000-01 and 2004-05 as compared to an improvement of 10 percentage points at the national level. Dramatic reductions in the poverty levels in a span of 5 years in Sindh is more an outcome of the comparison of two extreme points in terms of economic performance of the province. In 2000-01, Sindh was experiencing the second year of a severe drought and 2004-05 was an exceptional year for cotton output. One can safely infer that it is the reduction in poverty levels in Sindh and NWFP provinces that contributed to the reduction at the national levels. Whether this relationship is structural and sustainable or temporary due to the fluctuating performance of agriculture in these two provinces, can only be determined with a longer provincial time series and more indepth study.

b) The analysis of consumption based Gini coefficients at four points in time since 98-99 reveal that inequalities within Punjab and Sindh are marginally higher than the national estimate, and are significantly lower in NWFP and Balochistan, but have come closer to national estimates in the last few years. A similar scenario emerges when one estimates the ratio of the top $20 \%$ to the bottom $40 \%$ consumption quintile. 
c) A study of the shares of federal assistance to provincial PSDPs indicate that there is in-built bias in federal allocations toward NWFP and Balochistan. Punjab has consistently received less than its population share, Sindh almost equal or slightly less than its population share while NWFP and Balochistan have consistently received a higher share.

d) The ultimate aim of any development effort is to increase the capacities of its population in order to achieve a higher standard of living. The provision of higher human capital and economic and social capital reduces chronic poverty and improves income distribution in the long run. An assessment of non-consumption inequalities was carried out by a comparative analysis of $7 \mathrm{MDG}$ and 5 non-MDG indicators between 1998 and 2005. The analysis suggests reduced disparities in the provision of 7 out of 12 indicators, specifically education, water supply, sanitation, electricity and population using gas/kerosene oil at the national, provincial and intra-provincial level.

e) Intra-Punjab inequalities were also examined by dividing the 34 districts into the regions of north-west, south and central. Provincial allocations to these three regions strictly follow the population share formula, and apparently no attempt has been made to deliberately increase resource transfer to the lagging regions. However, nonconsumption disparities in most of the social and quality of living indicators have decreased during the period since 1998 across regions and within regions. However the absolute levels of disparities across regions are still high and are statistically significant. 


\section{References}

Center for Research on Poverty Reduction and Income Distribution (CRPRID), 2006, Millennium Development Goals Report, Islamabad.

World Bank, 2006, World Development Report, Washington D.C. 